\title{
'Last night I dreamt I went to Collinwood again': Vampire adaptation and reincarnation romance in Dark Shadows
}

Catherine Spooner, Lancaster University

\begin{abstract}
Tim Burton's 2012 film adaptation of the television soap opera Dark Shadows (196671) was controversial with fans, who saw it as failing to capture what they loved about the original. This article explores the gothic properties of doubling and repetition in the 1966-71 series and the ways in which they both pre-empt the discourses of adaptation and destabilize the notion of an 'original' text from which the adaptation departs. It argues that the reincarnation romance plot, in which an immortal being seeks to find the reincarnation of his or her lost love, extends the vampire/adaptation metaphor in significant new ways. The reincarnation romance also offers a useful model for understanding the adaptation of cult texts, as fans enact their own 'reincarnation romance' with the object of their passion. As such, it illuminates the responses of critics and fans to Burton's film and the broader problems of adapting cult texts. If the television vampire has, until very recently, been overlooked in favour of its cinematic variants, then the case of Dark Shadows reveals the value judgements informing this oversight and restores the television vampire to its full significance.
\end{abstract}

\section{Keywords}

vampire

Dark Shadows

gothic 
double

romance

adaptation

cult television

Tim Burton

In 2012, Warner Brothers released Dark Shadows, an adaptation of the gothic soap opera created and produced by Dan Curtis and screened on ABC between 27 June 1966 and 2 April 1971. The film, directed by Tim Burton and starring Johnny Depp as the vampire Barnabas Collins, met with a mixed reception from critics and audiences. Critics disliked the film's unevenness of tone, veering between comedy and melodrama, or felt that it was merely Burton and Depp going through an over-familiar routine. Many long-term fans, on the other hand, regarded the film as a travesty of the show that they loved, objecting to the off-hand, campy comedy of Seth GrahameSmith's script. In an earlier documentary, Curtis insisted that Dark Shadows is irreproducible. 'It's a strange kind of dream-like unique thing', he says. 'That's why no-one could ever copy it' (1991). But strangely enough, Dark Shadows has been copied multiple times, most of these by Curtis himself. In 1970 Curtis directed a film, House of Dark Shadows, starring the original actors and retelling Barnabas's story, with additional gore enabled by a theatrical release. ${ }^{1}$ He remade the same story as a high-budget twelve-part series for NBC, Dark Shadows: The Revival, in 1991. In 2004 he was executive producer of the pilot for another reboot, never shown on television but occasionally screened at fan conventions. Central to all of these adaptations, including Burton's, is the story of vampire Barnabas Collins's return to 
his ancestral home, Collinwood, 175 years after his death and his romance with his lost love, Josette DuPres.

Dark Shadows thus offers a unique insight into the significance of the vampire as a model or a metaphor for adaptation and for gothic adaptation in particular.

Vampire media is, as Ken Gelder has argued specifically of vampire film, 'citational', that is, it is intensely aware of its own precedents and refers to them continually and self-reflexively (2012). This is no less true of Dark Shadows: Harry M. Benshoff records how 'The show's writers [kept] a listing of well-known Gothic texts that they would consult and adapt as needed'. He continues,

This issue of adaptation was fairly unique to Dark Shadows - although other soap operas of the era undoubtedly borrowed narratives from women's romances and Hollywood melodramas, it was much more obvious that Dark Shadows was rewriting a fairly limited number of Gothic texts. (Benshoff 2011:25)

In Dark Shadows, the extreme citationality, not to say self-citationality, of the television series pre-empts and problematizes the process of adaptation, destabilizing the notion of an 'original' text from which the adaptation departs and inaugurating a proliferating series of copies. ${ }^{2}$ In a variety of ways, the series can be read as constantly in search of authenticity - the original that cannot be copied - at the same time that it perpetually undermines that original with a proliferating array of versions of any given story or character, foregrounding what Benshoff calls 'a deeply decentred subjectivity' (Benshoff 2011: 53). 
Dark Shadows' endless insistence both on recovering an original and on the copy as original reaches its apotheosis in its preoccupation with the reincarnation romance plot. This plot, in which an immortal being seeks to find the reincarnation of his or her lost love, extends the vampire/adaptation metaphor in significant new ways. In transferring this plot from imperial romance to the vampire narrative, Dark Shadows can claim an important and hitherto largely overlooked role in the formation of the late twentieth-century archetype of the sympathetic vampire. The reincarnation romance also offers a useful model for understanding the adaptation of cult texts, particularly from television to cinema. This is a form of adaptation that has received little attention in academia, although it is widely discussed in the fan discourses that it both distances itself from and solicits. As Henry Jenkins observes,

Organized fandom is, perhaps first and foremost, an institution of theory and criticism, a semistructured space where competing interpretations and evaluations of common texts are proposed, debated and negotiated and where readers speculate about the nature of the mass media and their own relationship to it. $(1992: 86)^{3}$

The case of Dark Shadows reveals that the narratives that drive cult texts also structure critical responses to them as fans enact their own 'reincarnation romance' with the object of their passion.

This article explores the gothic motifs of doubling and repetition in the 196671 series and the ways in which its formal properties pre-empt the discourses of adaptation. It then reflects more broadly on the role of the reincarnation romance in the adaptation process. As such, it illuminates the responses of critics and fans to 
Burton's film and the broader problems of adapting cult texts. If the main focus of adaptation studies is on literary texts adapted to film, then this essay suggests that models of adaptation based on this relationship do not adequately account for the markedly different value hierarchies between other media, and particularly between television and film. If the television vampire has, until very recently, been overlooked in favour of its cinematic variants, then the case of Dark Shadows reveals the value judgements informing this oversight and restores the television vampire to its full significance.

\section{1: Vampire adaptation}

Thomas Leitch, in an article entitled 'Vampire adaptation', suggests that

one of the hoariest clichés in the field [of adaptation studies] is that adaptations act like vampires in sucking the life out of the passive, helpless progenitor texts who enable their existence, often unwittingly or unwillingly, but are powerless to control their excesses. (2011: 5)

Pursuing the vampire metaphor through a series of films and television series (although not Dark Shadows), he suggests that vampires are equivocal, communicative (or in other words, contagious), collaborative and performative and in these guises reveal something rather different and more complex about the relationship between adaptations and their source texts. He eventually flips the clichéd view of the adaptation as a vampiric parasite, proposing instead that it is the literary texts themselves that, "precisely by being defined as literature, have become 
vampires... demand[ing] absolute devotion from academic acolytes' (Leitch 2011: 14).

Leitch's argument provides some useful insights into the vampire/adaptation metaphor. His article is necessarily generalizing, however, in that it picks out patterns and metaphors across contemporary culture. As such it aims to explicate adaptation through representations of vampires rather than examine what it means to adapt vampire narratives themselves. It is also focused specifically on literary adaptation. Dark Shadows does not comfortably fit this pattern in that it is a televisual text (lacking, as a daytime soap opera, the cultural cachet of either literature or film) and in that it both cites or adapts pre-existing literary texts and becomes a new source for televisual and filmic adaptation. If Dark Shadows as a cult text might also be said to 'demand absolute devotion from [its] acolytes', it does so within a strikingly different value system.

Film versions of TV series are usually continuations of an original story using the same cast and setting - the Star Trek films of the 1970s-80s are the most prominent example, although other series including Twin Peaks (1990-91), The XFiles (1993-2002) and Firefly (2002) have also been extended in this fashion, as Twin Peaks: Fire Walk With Me (Lynch, 1992), The X-Files (Bowman, 1998) and The XFiles: I Want to Believe (Carter, 2008) and Serenity (Whedon, 2005) respectively. These can only be described as adaptations in the very loosest sense. Since the 1990s, however, it has become increasingly common to 'reboot' successful TV franchises with a new cast, starting the original story afresh. The shows adapted in this way tend to possess a nostalgic value for viewers and are often associated with a cult audience: examples include The Addams Family (1964-66, adapted by Sonnenfeld, 1991), The Avengers (1961-9, adapted by Chechik, 1998), Charlie's Angels (1976-81, adapted by 
McG, 2000), Scooby-Doo (1969-86, adapted by Gosnell, 2002) and Bewitched (196472, adapted by Ephron, 2005). These adaptations are eagerly anticipated by fans but, with a few notable exceptions, are frequently met with disappointment and poor reviews on release. Burton's Dark Shadows clearly fits this model, although it is remarkable both for how closely it adapts the storyline of its source and for its association with a director celebrated for his distinctive vision and with a cult audience of his own. Dark Shadows, then, provides a particularly complex and condensed example of a more universal problem.

There is something about Dark Shadows, and specifically something about Barnabas Collins, its charismatic vampire played in the first TV series by Jonathan Frid, that facilitates adaptation. The cinematic vampire has repeatedly been referred to in terms of shadows, and thereby linked to the earliest forms of film technology. As Stacey Abbott writes in Celluloid Vampires, 'Made up of still images, ghostly shadows of the dead that are reanimated through technological means, film bears striking parallels with vampirism' (2007: 42). The vampire as shadow is in opposition to light, but also, more pertinently, the shadow is something that is a weaker image or repetition of something else. Vampires, and films, are inauthentic entities in that they are both copies of the living. Both, furthermore, can be copied multiple times. One of the key features of the vampire is its ability to reproduce itself outside of conventional biological structures. Jennifer Wicke argues that in Bram Stoker's novel, Dracula (1897), the mediation of the text through modern technologies - in particular, Mina's typewriter - produces a profoundly unstable, even vampiric text. She points out that Mina's typewriter has a function called 'Manifold' that enables it to make multiple copies in threes. She suggests 
This function is positively vampiric $[. .$.$] reverberating with the multiplicity of$ men Dracula is, the manifold guises of the vampire, and the copying procedure which itself produces vampires, each of which is in a sense a replica of all the others. Here we step into the age of mechanical reproduction with a vengeance, since the reproductive process that makes vampires is so closely allied to the mechanical reproduction of culture. (Wicke 1992: 476)

If, in Dracula, the text itself is vampiric, something similar could be said about the process of adaptation in Dark Shadows. Vampires, and vampire texts, produce multiple versions of themselves, seemingly as a matter of course. The business of producing replicas profoundly destabilizes a vampire original and the notion of an original or authentic text.

This is illustrated by the repeated preoccupation with Barnabas's story in adaptations of Dark Shadows. Barnabas was not part of Curtis's initial premise for the series, which explicitly drew on the gothic romance, with heroine Victoria Winters (Alexandra Moltke) arriving at ancestral mansion Collinwood as a governess and gradually uncovering the secrets of its eccentric family, while trying to discover her own mysterious ancestry. From the outset, the series demonstrates a self-conscious concern with its own genre-belonging: in the first episode, Victoria tells waitress Maggie (Kathryn Leigh Scott), 'You make it sound like some old English novel with rattling chains and ghosts in the corridors'. Maggie responds rhetorically, 'You think that's wrong?'. Victoria's comment anticipates Curtis's introduction of a series of supernatural occurrences in an effort to boost flagging ratings, including the ghost of Josette DuPres (Kathryn Leigh Scott) and 'phoenix' Laura Collins (Diana Millay). These were overshadowed, however, by the arrival of Collins family ancestor 
Barnabas in the form of a 175-year-old vampire ten months into the series' original run. The vampire storyline and Jonathan Frid's performance proved such a runaway success that Barnabas, who Curtis had intended to write out of the series after a few months, became its central and most enduring character. Barnabas's entrance in episode 210 is, significantly, construed as a return even before he has appeared in the show. This moment, rather than the earlier storylines, is the one to which each of the Dark Shadows adaptations returns, sometimes allowing Victoria's arrival to coincide with Barnabas's, but always relocating the vampire to the centre of the story.

The adaptations' repeated return to the moment of Barnabas's return is thus construed as a sort of return to origins for the series: although not part of its 'original' conception, it is the moment at which the series finds its identity. As such it establishes a pattern for subsequent vampire television series, in which elaborate origin stories, often conveyed through extended flashback sequences, augment characters' individual stories. ${ }^{4}$ In Dark Shadows, however, it is not Barnabas's past that becomes the series' origin story, but the act of his return, and this functions metatextually as an origin for the series itself, constructed through its regenerated relationship with its audiences and its plot. The DVD reissues of the series in 2002 and 2012 reflected this logic, beginning 'Collection 1' with Barnabas's entrance and renaming the earlier episodes 'The Beginning'.

The Barnabas story is more than an origin story for Dark Shadows itself, however: it is also an origin story for what has become a dominant cultural myth of the late twentieth and early twenty-first centuries: the sympathetic vampire. Linda Badley was one of the earliest to observe that 'The modern sympathetic vampire emerged in the late 1960s with Dark Shadows' Barnabas Collins, soap opera hero and reluctant bloodsucker', a trend that developed through the 1970s and became 
canonized in Anne Rice's Interview With the Vampire of 1976 (Badley 1996: 105). ${ }^{5}$

Nevertheless, Badley's assessment of the series amounts to two sentences, while other key 1990s works on vampires, published prior to the series' DVD release, either fail to recognize Barnabas as a reluctant vampire or fail to recognize him at all. ${ }^{6}$ The ephemerality of television as a medium before the advent of VCR, its relatively low cultural status (particularly in the case of daytime television) and the fact that Dark Shadows was not broadcast in the United Kingdom where much gothic scholarship was initially centred, meant that Barnabas' influence on the subsequent generation of vampires was overlooked or downplayed. Dark Shadows can thus be viewed as a kind of lost original for the sympathetic vampire motif.

\section{2: Doubling}

Dark Shadows is distinctive for its excessive concern with repetition at the level of both form and content, a concern that anticipates and invites its reading as adaptation. Linda Hutcheon famously explains audience enjoyment of adaptation as the pleasure of 'repetition with variation $[\ldots]$ the comfort of ritual combined with the piquancy of surprise' (2006: 4). In Dark Shadows, the pleasure of repetition is also the uncanniness of doubling. Helen Wheatley notes that gothic television tends to feature 'a proclivity towards the structures and images of the uncanny (repetitions, returns, déjà vu, premonitions, ghosts, doppelgangers, animated inanimate objects and severed body parts, etc.)' (2006: 3). She goes on to stress that the domestic context of the medium's reception enhances the uncanny properties found in gothic texts, which are 'therefore located in the moments in gothic television in which the familiar traditions and conventions of television are made strange, when television's predominant genres and styles are both referred to and inverted' (Wheatley 2006: 7-8). In Dark Shadows, 
the uncanny is not only a thematic device but is also built in to the very fabric of the show. Dark Shadows 'makes strange' the familiar conventions of the daytime soap, perhaps the ultimate domestic genre. As Benshoff points out, prior to the introduction of VCR, it was assumed by production personnel that the average soap viewer would only see two episodes a week, which 'necessitated a high level of repetition and reiteration of narrative events' (2011: 42). This practical necessity was married to a gothic preoccupation with repetition that permeated every aspect of the series' production, from visual patterning in individual shots to props, characters and storylines. Even the show's title is doubled: 'Dark Shadows' is a tautology, as all shadows are, by definition, dark - admittedly, some may be darker than others, but 'light shadows' is nonsensical. The title is therefore a shadow of itself. From the outset, the show signals its excessiveness: so dark they named it twice.

Dark Shadows also shadows a series of canonical literary texts. Dan Curtis explicitly acknowledges that 'Many stories I ripped right off out of the classics', citing the Quentin Collins storyline as a version of The Turn of the Screw (1898), and Victoria Winters' arrival at Collinwood as a version of Jane Eyre (1847) (Curtis 1991; Inside the Shadows 2012). Other inspirations include Frankenstein (1818), Wuthering Heights (1847), The Strange Case of Dr Jekyll and Mr Hyde (1886), The Picture of Dorian Gray (1890-91), Dracula (1897), Poe's short stories and Lovecraft's Cthulhu Mythos. Many of these narratives are repeated more than once: as Jonathan Frid reported, the writers 'went through all the stories three or four times. We started repeating ourselves, and the show burned out' (quoted in Benshoff 2011: 25). The Turn of the Screw, for example, inspires not only the ghosts of Quentin Collins (David Selby) and Beth Chavez (Terry Crawford) in episodes 639-700 but 
also the ghosts of Gerrard Stiles (James Storm) and Daphne Harridge (Kate Jackson) in 1109-71.

Like numerous iconic gothic narratives including The Castle of Otranto (1764), Frankenstein, Jekyll and Hyde and Dracula, Curtis located the genesis of Dark Shadows in a dream. His vision of a young girl on a train arriving at a crumbling old mansion was realized as Victoria Winters' journey to Collinwood in Episode 1. This sequence, with Alexandra Moltke as Victoria reflecting in voice-over on her past and her future at Collinwood, also strongly recalls the opening sequence of Daphne du Maurier's Rebecca ([1938] 1962) and Joan Fontaine's opening voice-over as Mrs de Winter in Hitchcock's 1940 adaptation; the shared character name is not coincidental. Rebecca's famous opening line, 'Last night I dreamt I went to Manderley again', offers another form of uncanny repetition or doubling between the dream state and the remembered past (du Maurier [1938] 1962: 5). The allusion is underlined by the shot of crashing waves in the series' credit sequence, recalling a similar shot in the opening sequence of Hitchcock's Rebecca. The mise-en-scène of Burton's film makes this allusion still more explicit in its lingering shot of elaborate ironwork gates (also recalling Welles's Citizen Kane, 1941, and several films in Burton's own oeuvre). ${ }^{7}$ The opening to the series thus offers a kind of intertextual frenzy that is heightened in each successive retelling. The multiple repetitions of texts in the series as a whole are so baroque that it exceeds conventional processes of adaptation, recalling what Kamilla Elliott has called 'adaptation as compendium', forming a kind of inventory of gothic tropes and narrative conventions (2010). Significantly, Elliott coins this phrase to discuss Tim Burton's Alice in Wonderland (2010), the film that he made immediately before Dark Shadows. 
Repetition does not only occur in Dark Shadows through the medium of intertextuality. Over its five-year run, timeslip and parallel reality episodes enabled the regular actors to play multiple characters - sometimes even multiple versions of the same character. Even Jonathan Frid appeared as Barnabas's son from a parallel reality, Bramwell Collins. This preoccupation with doubling is signalled right from the opening sequence of the first episode, in which Victoria Winters is seen reflected in the window of the train she is travelling on (Figure 1) [INSERT FIGURE 1 HERE] while her voice-over intones, 'My journey is beginning - a journey that I hope will open the doors of life to me, and link my past with my future'. It is a strikingly self-reflexive moment. The train window operates as a reflective screen, visualizing the notion of the self split between past and future. It is a mirror as a portal ('the doors of life') through which Victoria, like Lewis Carroll's Alice, might step into a parallel world. This further allusion is reinforced as the episode progresses by two flashback sequences to Victoria's past initiated when Victoria catches sight of her reflection in a mirror, a rapid dissolve giving the impression of movement through the reflective surface (Figure 2) [INSERT FIGURE 2 HERE]. The train window also suggests a television screen and recalls Abbott's invocation of 'still images, ghostly shadows of the dead that are reanimated through technological means' (2007: 42). Here, a slippage operates between television and cinema: the stock film footage of a train with illuminated windows speeding in the dark intercut with the interior video footage suggests the rapid movement of a film reel. Literature, cinema and television are drawn on indiscriminately to conjure Maxim Gorky's 'kingdom of shadows', a spectral world of replication (1896: 5). Meanwhile Victoria insists that the people she is about to meet are 'still only shadows in my mind, but [...] will soon fill the days and nights of my tomorrows', indicating the future as a realm of shadows existing 
within an interior psychic space that implicitly doubles the material world in the present. None of these allusions are carefully or precisely worked through, but cumulatively they suggest a sense of porousness, not only between past and present, psychological and material worlds but also between media and genres. Victoria Winters is, at this stage, the conduit or the medium through which these worlds meet and mingle, anticipating her later role in the séance plot, in which she channels the ghost of Sarah Collins and is then herself transported back into the past.

The formal preoccupation with doubling comes to a head with the series' emphasis on portraits, in particular, those of Josette DuPres and Barnabas Collins. In multiple shots the characters are doubled on-screen with their own images; in episode 70 , the ghost of Josette even descends from her portrait to wander the corridors of Collinwood as Victoria had anticipated. This doubling is particularly pronounced with Barnabas's portrait. In the episodes following his arrival at Collinwood, both he and the other characters repeatedly return to the portrait and comment on his resemblance to it. In episode 211, Barnabas is admitted by the housekeeper, catches sight of his portrait and moves towards it, his shadow preceding him and creating an uncanny threefold image that resolves into two as vampire, shadow and portrait appear to meet and merge (Figure 3) [INSERT FIGURE 3 HERE]. He turns, and is framed alongside his likeness as he announces, 'It's Barnabas Collins', the portrait a verification of his identity (Figure 4) [INSERT FIGURE 4 HERE]. This is reiterated in episode 212, as Elizabeth Collins Stoddard (Joan Bennett) remarks on the 'uncanny', 'extraordinary' and 'remarkable' resemblance, while in episode 214, Carolyn Stoddard (Nancy Barrett) comments that 'it's more than a resemblance - it's almost as if - it were exactly a portrait of him'. Repeated match shot dissolves at the 
end of episodes 212 and 214, in which the portrait and Barnabas appear to merge into one another, work to underline the unity of vampire and representation.

Barnabas's portrait thus proves a guarantee of authenticity, of family resemblance, in a way that is familiar from countless gothic novels. Yet the portrait is itself bewilderingly multiple and subject to replication. Within the series, Barnabas commissions Sam Evans to paint a modern portrait - so there are two different Barnabas portraits in circulation. More uncannily still, the real prop disappeared from the studio during the filming of the movie House of Dark Shadows, and so a second version of the eighteenth-century portrait had to be made and featured in later episodes of the show. In episode 212, precocious child David Collins (David Henesy) insists on the difference between the portrait and Barnabas, identifying the former as angry and the latter as sad, remarking of the 'real' Barnabas, 'he seems to be remembering something that he's lost a long time ago'. David here points to a fundamental truth about the portrait: that it shows Barnabas as a human, while he is now a vampire. The thing that he lost a long time ago may be Josette, but it is also his humanity. Despite the series' attempts to unify vampire and image, therefore, an excess always remains, like the uncanny shadow falling across the portrait in Episode 211.

Because of budgetary constraints, most episodes of Dark Shadows featured a maximum of five actors, and the portrait often stands in for Barnabas when he is not featured in an episode, effectively becoming an actor in its own right. As Harry Benshoff states, 'even when Barnabas is not in a given episode, the mise-en-scène works to recall him' (Benshoff 2011: 48). In episode 215, for example, Willy Loomis is as powerfully affected by the sight of the portrait as he might be by recognizing Barnabas himself. In episode 405, the witch Angelique (Lara Parker) attempts to 
exploit this power of affectivity by artificially ageing Josette's portrait to that of a rotting corpse, but Barnabas refuses to be deceived by the illusion. Nevertheless, Angelique's actions acknowledge the way in which portraits within the series embody rather than merely represent the original and thus can trigger powerful emotional responses. In Dark Shadows, portraits incarnate the subjects that they depict and thus anticipate my final theme, the reincarnation romance.

\section{3: Reincarnation}

Dark Shadows animates a tension between monster narratives' recurrent thematic interest in incarnation and a critical concern with 'adaptation as incarnation' identified by Kamilla Elliott in Rethinking the Novel/Film Debate (2003: 161). Elliott explains that one characteristic critical stance in relation to film adaptations of literary texts is to regard them as a form of 'the Christian theology of the word made flesh, wherein the word is only a partial expression of a more total representation that requires incarnation for its fulfilment' (Elliott 2003: 161). Thomas Leitch extrapolates from this theory to suggest that 'monster films embody Elliott's incarnational concept more fully than any other films: Practically all of them take incarnation as their subject. The relation between body and spirit is at the heart of monster films' (Leitch 2007: 106). Nevertheless, while Dark Shadows is as concerned with the relationship between body and spirit as any other horror text, its preoccupation with doubling and repetition makes it less incarnational than reincarnational. Rather than attempt to embody a previously incomplete text, it seeks to regain a lost original through endless versions and re-versions. If this description of reincarnation is theologically hazy, this is because the model of reincarnation that the show uses is one derived not from eastern religion but from imperial romance. 
The orgy of repetition that takes place in Dark Shadows can be read as a form of narrative disturbance attending a particular gothic convention identified by Eve Kosofsky Sedgwick in which 'It is the position of the self to be massively blocked off from something to which it ought normally to have access' (1986: 12). This blockage could be applied to several characters and storylines but the most obvious is, of course, Barnabas's separation from his lost love, Josette - the impetus for the series' 'reincarnation romance'. Barnabas is presented as pursuing an almost pathological search for origins, in that he is compelled not only to restore the Old House to its 'original' state but also to recreate Maggie Evans - and in subsequent versions, Victoria Winters - in Josette's image. The women in these storylines exhibit different degrees of agency: in the 1991 revival series, and in Burton's film, Victoria Winters embraces her dual identity as Josette; Barnabas's treatment of Maggie Evans in the first series and in House of Dark Shadows is much more coercive. As Sedgwick argues, 'the lengths there are to go to reintegrate the sundered elements - finally, the impossibility of restoring them to their original oneness - are the most characteristic energies of the Gothic novel' (1986: 13). These energies result in a distinctive pattern in which 'the difficulty the story has in getting itself told is of the most obvious structural significance' (Sedgwick 1986: 13). In other words, Barnabas's pathological drive towards origins manifests in the convoluted time lines, elaborate dream sequences and above all frenzied doubling and repetition for which Dark Shadows is famous. In terms of adaptation, the search for origins can be read as a search for authenticity: the obsessiveness with which the different versions of Dark Shadows return to and reiterate the Barnabas/Josette story suggests a desire to identify the 'real' story underpinning the series, at the same time that each new adaptation further destabilizes a unitary reading of the text. 
What I call the reincarnation romance plot has become so familiar in vampire cinema that Tim Burton can claim, in an interview on Dark Shadows, that 'vampires often just happen to run into their old loves' (Dark Shadows: The Legend Bites Back 2012). However, despite Burton's assertion, the reincarnation romance is not a traditional feature of vampire narrative. Its literary source is H. Rider Haggard's imperial gothic novel She (1888), in which the immortal queen Ayesha seeks to be reunited with her lost love Kallikrates, who is reincarnated in the form of a young English explorer. Ayesha is not a vampire but has had a significant influence on twentieth-century vampire narrative, seen also in the character of Queen Akasha in Anne Rice's Vampire Chronicles. The plot entered cinema via the similarly themed 1932 Universal horror film The Mummy (Freund, 1932). It also indirectly recalls the undying love beyond the grave of Wuthering Heights, a recurrent influence on Dark Shadows (Jonathan Frid's parallel time zone character, Bramwell Collins, took his name from Emily Brontë's brother Branwell and his star-crossed romance with Catherine Harridge is inspired by Heathcliff's romance with Catherine Earnshaw in Brontë's novel). As I have established, Dark Shadows characteristically condenses gothic tropes and motifs from multiple narratives into a single ongoing plot. In combining the reincarnated lost love plot of imperial gothic with the vampire plot, the show enabled the emergence of vampire romance and set a new narrative paradigm that was repeated endlessly in vampire films of the 1970s, from Blacula (Crain, 1972) to Love at First Bite (Dragoti, 1979).

Most significantly, the reincarnation romance plot was repeated in the 1973 TV movie of Dracula directed by Dan Curtis and scripted by Richard Matheson, the source of James V. Hart's screenplay for Francis Ford Coppola's Bram Stoker's Dracula (1992) (Auerbach 1995: 209, vol. 16). Curtis imported the reincarnation 
romance that he had used to such great success in Dark Shadows to the plot of Stoker's classic novel, the novel that has more than any other determined the cinematic form of the vampire in the twentieth and twenty-first centuries. This adds a further layer of complexity to the adaptation process enacted by Burton's film. Seth Grahame-Smith comments in the Blu-Ray extras to the film that his screenplay is a 'homage to Bram Stoker's Dracula', not specifying whether he means Coppola's film or Stoker's novel - although his gloss, 'the idea that two people who are separated by death and by time can find each other', is clearly influenced by the Coppola film narrative (Dark Shadows: The Legend Bites Back 2012). Thus a strange kind of circularity operates: Burton's movie may be a tribute to Coppola's film, but Coppola's film derives its plot from Dan Curtis and thus indirectly from Dark Shadows. Alternatively, if Grahame-Smith is referring to Stoker's novel - which notoriously does not feature a romance between Dracula and Mina - then the presence of the reincarnation romance suggests that Coppola's film, and thus indirectly Dark Shadows, has come to overshadow Stoker's 'original' vampire narrative, and the drive towards origins is yet again frustrated. Despite Burton's claim in the same interview that he is taking the story 'back to the source', exactly which source he means is unclear (Dark Shadows: The Legend Bites Back 2012). Grahame-Smith's assertion that Burton's 'huge horror film vocabulary' brings a 'real authenticity' to the filmmaking process reroutes the point of origins to the director himself, positing him as auteur and, significantly, constructing this authenticity through his fan credentials (Dark Shadows: The Legend Bites Back 2012). In promotional materials for the film, both Burton and Depp present themselves as Dark Shadows fans - both appropriate the customary fan description of running home to watch it, and Depp states that, 'I felt as if I were the one under a spell', suggestively placing himself in the position of 
Barnabas (who in the series is enchanted by Lara Parker's Angelique) (Salisbury 2012: 5). ${ }^{8}$

Ultimately, the reincarnation romance plot comes to self-reflexively structure the adaptation process, which in Tim Burton's words also figures as an attempt to capture a lost love. Interviewed by Mark Salisbury, Burton states,

I've done things where you could say it's a remake but I've never considered this to be one, because there's nothing to re-make [...] So we had to sort of capture the spirit of that elusive thing of why you love something. (2012: 13)

Burton's insistence that 'there's nothing to re-make' explicitly recalls Curtis's assertion that 'no-one could ever copy it' (Curtis 1991); Burton defensively implies that he is not copying Curtis's original but channelling its essence. His words suggest what Elliott calls the 'psychic concept of adaptation', whereby the adaptor tries to capture the 'spirit of the text' (Elliott 2003: 136). However, here it is not the spirit of the text that it is sought but rather the viewer's emotional response to it: 'the spirit of that elusive thing of why you love something'. Value is located not in the text itself but in the passion that it inspires in its audience.

Similarly, screenwriter Seth Grahame-Smith suggests of the reincarnation romance plot, 'Even if it's not quite the same person, it is the same spirit' (Dark Shadows: The Legend Bites Back 2012). In suggesting that the person is not quite the same but the spirit continues, Grahame-Smith configures the reincarnation romance plot as itself a kind of adaptation. Again recalling Elliott's 'psychic theory of adaptation', the reincarnated lover - like the film - is both physically different and spiritually the same. Burton's comment, 'we had to sort of capture the spirit of that 
elusive thing of why you love something' thus plays adaptation as a kind of reincarnation romance, in which the director plays Barnabas Collins, the original Dark Shadows is Josette and the film is Maggie Evans/Victoria Winters, a vehicle for her beloved predecessor's spirit. The curious effect of this playing out of the reincarnation romance is to make the film a victim of competing claims of authenticity: is the new version more 'real' than its earlier counterpart, being rooted in the present, and haunted by its earlier incarnation? Or is the lost lover the 'original' and therefore the most authentic, and subsequent versions inferior copies?

The model of adaptation as reincarnation romance sheds light on fans' disappointment with the Burton movie, and indeed other attempts to recapture the appeal of cult television shows. The film was eagerly anticipated in the fan community, sometimes with a sense of dread: blogger Wendy Brydge confesses,

as the months passed by, I read every article, watched every trailer for this new Burtonized film. I joined in with other die hard fans, 'Dark Shadows Purists', in blasting the project and touting it as blasphemy. I even convinced myself that there was no way I would ever watch this monstrosity'. (Brydge 2012)

Although Brydge admits to being pleasantly surprised by the film, this is not a typical response. An IMDB reviewer going by the name of melody23 is more representative when she states,

I wonder if Depp was watching the same series I was. As much as I loved the original Barnabas, I see no trace of the character in his interpretation $[\ldots]$ 
Depp and Burton seem to have nothing but contempt for the original series. I'm sorry, but flawed and bad as it could be, Dark Shadows was still far more compelling on its tiny budget than this movie was with its huge one. (2012)

The more elusive the appeal of the original show and the stronger the desire to recapture its emotional affect, the more the drive to recapture it will be frustrated. Burton and Depp's positioning of themselves as fans is significant in this respect. Dark Shadows is, moreover, a particularly interesting case study in terms of its fandom. While its creator, Dan Curtis, has a strong claim to being what Helen Wheatley calls a 'Gothic auteur' (Wheatley 206: 150), its fans had an unusually strong role in shaping its direction. As Williamson, Wheatley and Jowett and Abbott all explain, the retention of Barnabas as a regular character and his increasingly sympathetic portrayal was a direct result of fan intervention as Jonathan Frid was bombarded with fan mail, much of it picking up on cues such as Barnabas's professed loneliness to read him as sympathetic.

Fan responses to Dark Shadows place the production and valuation of vampire 'originals' and 'copies' in a new light: the 'original' Barnabas as envisioned by Curtis, a purely evil monster, is not that which provokes the desired emotional response. Ien Ang has written how fans seek 'emotional realism' within texts, in other words while stories may be fantastical in the context of fans' lives, the emotions that they deal with are perceived as true (1985). The notion of Barnabas as lonely, guiltridden and driven by obsessive love and regret evidently struck a chord with his audience more than the notion of him as a manipulative, cold-blooded killer - and became the 'real' Barnabas against which other versions are measured. A fan review of the 2004 pilot on the web, for example, writes, 
Just for the record - I don't give a damn about Dan Curtis' vision. My judgment is based on what ended up on screen, the story told and the characters whose lives I'm supposed to care about. Curtis got to tell his version undiluted in the motion picture House of Dark Shadows. It was fun. It also lacked nearly every single element that made me care about the show in the first place. And multiple reports from those involved say how much Curtis opposed the whole idea of making Barnabas the vampire sympathetic at all. (Blue 2010)

The blogger, going by the name of Zahir Blue, evidently prioritizes caring about the characters over an authentic or an original vision - the director as auteur. Emotional authenticity is posited as the chief criterion of value and by extension fidelity to the 'original'. As the blogger continues: 'One reason I still prefer Frid's Barnabas over Ben Cross is that the former smiled and seemed to mean it' (Blue 2010).

Tim Burton's Dark Shadows, however, despite Burton's protestations, was widely read as failing to capture emotional authenticity. Roger Ebert, for example, articulated a representative opinion that

[Depp's] performance is arch and mannered, as perhaps it should be, but so is everyone else's; the result falls between satire and lampoon, and creates such a distance between characters and style that nobody seems to much care what happens. (2012) 
It is in this apparent emotional lacuna that fan responses to the film foundered, Burton failing to resurrect their lost love. Burton, like Curtis, has claims to 'Gothic auteur' status: the catalogue to MOMA's exhibition of his artwork describes him as 'an uncompromised visionary - a modern auteur' with 'a style so distinctive it is referred to in the vernacular as "Burtonesque", (He and Magliozzi 2009: 17). His films are remarkable for the way in which they stamp a unique and distinctive vision on a variety of different genres and source material. This emphasis on style, however, manifested in the widely praised visual elements of the film such as costume, production design, art direction and special effects, is at odds with fans' valuing of emotional authenticity. ${ }^{9}$

\section{Conclusion}

The significant feature of Dark Shadows' reincarnation romance is what it reveals about the adaptation of cult texts. If 'classic' literature is conventionally valued more highly than the apparently parasitic medium of film, then the expectation is that film and certainly auteur-directed film with high production values such as Burton's Dark Shadows - is valued more highly than low-budget, rapidly produced daytime soap opera with its wooden acting, repetitive storylines and flimsy sets. It is thus perplexing when fans reject big-budget adaptations. But viewing the adaptation of cult television as reincarnation romance, in which reunion with the lost love is forever frustrated, demonstrates the importance of the viewer's emotional bond with the text. This viewer longs for the story to be repeated as this is the only way that their love can be restored to them, but each further repetition both holds out the promise of reunion and prolongs their separation from the original. The emotional resonance of this model underscores its pervasiveness in later twentieth-century and twenty-first 
century vampire media. It indicates the importance that television has to the advancement of contemporary vampire narrative. Dark Shadows did not just rehash familiar gothic narratives and conventions in televisual form: it initiated a cultural shift towards a new kind of vampire that would go on to dominate subsequent representations. Barnabas Collins should be viewed as more than just a footnote to the development of the twentieth-century vampire; rather, he is one of its most foundational figures.

\section{References}

Abbott, S. (2007), Celluloid Vampires: Life after Death in the Modern World, Austin, TX: University of Texas Press.

(2010), 'Dark Shadows', in Stacey Abbott (ed.), The Cult TV Book, London: I. B Tauris, pp. 205-08.

Ang, I. (1985), Watching Dallas: Soap Opera and the Melodramatic Imagination, London: Methuen.

Auerbach, N. (1995), Our Vampires, Ourselves, Chicago: University of Chicago Press.

Badley, L. (1996), Writing Horror and the Body: the Fiction of Stephen King, Clive Barker and Anne Rice, Westport CT: Greenwood Press. 
Benshoff, Harry M. (2011), Dark Shadows, Detroit, MI: Wayne State University Press.

Bewitched (1964-72, USA: ABC).

Blue, Z. (2010), 'Dark Shadows 2004', Night Tinted Glasses, 19 July, http://zahirblue.blogspot.co.uk/2010/07/dark-shadows-2004.html. Accessed 30 August 2016.

Brydge, W. (2012), 'Tim Burton's Dark Shadows: A review by a DS Purist', Seeker of Truth, 27 May, https://wendylovesjesus.wordpress.com/2012/05/27/timburtons-dark-shadows-a-review-by-a-ds-purist/. Accessed 6 April 2017.

Burton, Tim (2012), Dark Shadows, USA: Warner Bros. Pictures.

Charlie's Angels (1976-81, USA: ABC).

Cousin, B. (2015), 'I ran home to watch Dark Shadows and lived to tell about it', The Collinsport Historical Society, http://www.collinsporthistoricalsociety.com/2015/11/i-ran-home-to-watchdark-shadows-and.html. Accessed 13 July 2017.

Crawford, J. (2014), The Twilight of the Gothic? Vampire Fiction and the Rise of the Paranormal Romance, 1991-2012, Cardiff: University of Wales Press. 
Curtis, Dan (1970), House of Dark Shadows, USA: Metro-Goldwyn-Mayer. (1991), Dark Shadows: Behind the Scenes, USA: Dan Curtis Productions.

Dark Shadows (1966-71, USA: ABC).

Dark Shadows: The Legend Bites Back (2012), Blu-Ray Extra to Dark Shadows, dir. Tim Burton, USA: Warner Bros. Pictures.

Du Maurier, D. ( [1938] 1962), Rebecca, Harmondsworth: Penguin.

Ebert, R. (2012), 'Dark Shadows', RogerEbert.com, 9 May, http://www.rogerebert.com/reviews/dark-shadows-2012. Accessed 30 August 2016.

Elliott, K. (2003), Rethinking the Novel/Film Debate, Cambridge: Cambridge University Press. (2010), 'Adaptation as Compendium: Tim Burton's Alice in Wonderland', Adaptation, 3:2, pp. 193-201.

Firefly (2002, USA: Fox).

Gelder, K. (1994), Reading the Vampire, London: Routledge. 
(2012), New Vampire Cinema, London: BFI/Palgrave Macmillan.

Gorky, M. ([1896] 1996), 'A review of the Lumière Programme at the NizhniNovgorod Fair', in C. Harding and S. Popple (eds), In the Kingdom of Shadows: A Companion to Early Cinema, London: Cygnus Arts, pp. 5-6.

He, J. and Magliozzi, R. (2009), Tim Burton, New York: The Museum of Modern Art.

Hitchcock, Alfred (1940), Rebecca, USA: Selznick International Pictures.

Hutcheon, L. (2006), A Theory of Adaptation, London and New York: Routledge.

Inside the Shadows (2012), DVD extra to Dark Shadows: The Original TV Series: The Barnabas Collins Episodes, dir. Dan Curtis, USA: Dan Curtis Productions.

Jenkins, H. (1992), Textual Poachers: Television Fans and Participatory Culture, London: Routledge.

Jowett, L. (2014), 'Stuffing a rabbit in it: Character, universe and time in the Whedonverses', in R. V. Wilcox, T. R. Cochran, C. Masson and D. Lavery (eds), Reading Joss Whedon, Syracuse, NY: Syracuse University Press, pp. $297-311$. 
Jowett, L. and Abbott, S. (2013), TV Horror: Investigating the Dark Side of the Small Screen, London: I. B. Tauris.

Lampley, Jonathan M. (2015), 'Dark Shadows', in D. Lavery (ed.), The Essential Cult TV Reader, Lexington: University Press of Kentucky, pp. 84-89.

Leitch, T. (2007), Film Adaptation and Its Discontents: From Gone With the Wind to the Passion of the Christ, Baltimore MD: Johns Hopkins University Press.

(2011), 'Vampire adaptation', Journal of Adaptation in Film and Performance, $4: 1$, pp. $5-16$.

melody23 (2012), 'Insults about half the original fans', IMDB, 11 May, http://www.imdb.com/title/tt1077368/reviews. Accessed 6 April 2017.

Salisbury, M. (2012), Dark Shadows: The Visual Companion, London: Titan Books.

Scooby-Doo (1969-86: USA: Hanna-Barbera/CBS/ABC).

Sedgwick, Eve K. (1986), The Coherence of Gothic Conventions, rev. 2nd ed., London: Methuen.

Silver, A. and Ursini, J. (1997), The Vampire Film: From Nosferatu to Interview with the Vampire, rev. 3rd ed., New York: Limelight. 
The Addams Family (1964-6, USA: ABC).

The Avengers (1961-9, UK: Associated British Corporation/ITV).

The X-Files (1993-2002, USA: Fox).

Twin Peaks (1990-91, USA: ABC).

Spooner, C. (2017), Post-Millennial Gothic: Comedy, Romance and the Rise of Happy Gothic, London: Bloomsbury.

Wheatley, H. (2006), Gothic Television, Manchester: Manchester University Press.

Wicke, J. (1992), 'Vampiric typewriting: Dracula and its media', English Literary History, 59:2, pp. 467-93.

Williamson, M. (2005), The Lure of the Vampire: Gender, Fiction and Fandom from Bram Stoker to Buffy, London: Wallflower Press.

\section{Contributor details}

Catherine Spooner is Professor of Literature and Culture at Lancaster University, UK. She has published widely on gothic literature, film, television and popular culture, including the books Fashioning Gothic Bodies, Contemporary Gothic and Postmillennial Gothic: Comedy, Romance and the Rise of Happy Gothic. She has also co- 
edited The Routledge Companion to Gothic (with Emma McEvoy), Monstrous Media/Spectral Subjects: Imaging Gothic from the Nineteenth Century to the Present (with Fred Botting) and Return to Twin Peaks: New Approaches to Materiality, Theory and Genre on Television (with Jeffrey Weinstock). She was co-president of the International Gothic Association 2013-17.

\section{Contact:}

Department of English Literature and Creative Writing, County College, Lancaster University, Lancaster, LA1 4YD, UK.

E-mail: c.spooner@lancaster.ac.uk

Notes

\footnotetext{
${ }^{1}$ Another feature film adaptation by Dan Curtis, Night of Dark Shadows, was released in 1971 but did not feature Barnabas Collins.

${ }^{2}$ Although Linda Hutcheon (2006) distinguishes between adaptation and allusion, this position has been revised by a number of scholars. Leitch suggests that 'The slippery slope between adaptation and allusion cannot be divided into discrete stages because it really is slippery' (2007: 126). Following Leitch, I argue that Dark Shadows is both citational and adaptive in different measures throughout its 1250-episode run, and attempting to disentangle the two would be counterproductive.

${ }^{3}$ Dark Shadows has a long-standing fandom dating back to the original television broadcasts and incorporating discussion on online forums (the main focus of this article), but also the Dark Shadows Wiki, YouTube videos, fan art, fan fiction, dramatic performances, role-playing games and meetings and conventions. There are
} 
also a number of licensed spin-offs including a series of Big Finish audio-dramas featuring members of the original cast and a variety of comics and novelizations. ${ }^{4}$ Examples include Buffy the Vampire Slayer (1997-2003), Angel (1999-2004), True Blood (2008-14) and The Vampire Diaries (2009-17), which generated an entire origin narrative, appropriately titled The Originals (2013-present). Lorna Jowett memorably refers to the process of filling out character through formal devices that enable 'the (de)construction of subjectivity over time' as 'Stuffing a Rabbit in It' [this is derived from a quotation from Dollhouse 'The Target' 1.2] (2014: 297).

${ }^{5}$ There is an earlier literary example of a vampire who provides a first-person account of his existence and describes an increasing self-disgust in the nineteenth-century serial Varney the Vampire (1845-47), but the text was out of print for most of the twentieth century and therefore its influence on popular culture was limited. Similarly, Williamson notes two Universal horror films, House of Dracula (1945) and The Vampire's Ghost (1945), that portray early, undeveloped versions of the sympathetic vampire (2005: 32-33).

${ }^{6}$ Auerbach (1995) and Silver and Ursini (1997), for example, do not discuss Dark Shadows in these terms and Gelder (1994) does not mention it at all. Reading Barnabas as a 'sympathetic' or a 'reluctant' vampire becomes more prevalent in criticism post-dating the release of the series on DVD in 2002. Examples include Abbott (2010: 205-06), Crawford (2014: 50-52), Jowett and Abbott (2013: 205), Lampley (2015: 85), Wheatley (2006: 155) and Williamson (2005: 32). Nevertheless Dark Shadows remains a blind spot in many scholarly works.

${ }^{7}$ For further discussion of the ironwork gate motif in Burton's films, see Spooner (2017: 63-64). 
${ }^{8}$ According to The Collinsport Historical Society, wildly fluctuating scheduling among local broadcasters means that this is unlikely for a high proportion of the original viewers. However, a 1971 news story in the San Antonio Express that described children disregarding their own safety to get home in time for the programme has become legendary (Cousin 2015).

${ }^{9}$ For more on Burton's visual style see Spooner (2017: 49-66); for more on the discordance between the film's comic sensibility and Dark Shadows fans' emotional expectations see Spooner (2017: 132-35). 